\title{
Effects of nutritional supplementation for HIV patients starting antiretroviral treatment: randomised controlled trial in Ethiopia
}

\author{
OPEN ACCESS
}

\begin{abstract}
Mette F Olsen research fellow ${ }^{1}$, Alemseged Abdissa doctoral researcher ${ }^{2}$, Pernille Kæstel associate professor ${ }^{1}$, Markos Tesfaye doctoral researcher ${ }^{3}$, Daniel Yilma doctoral researcher ${ }^{4}$, Tsinuel Girma doctoral researcher ${ }^{5}$, Jonathan $\mathrm{C}$ K Wells professor ${ }^{6}$, Christian Ritz biostatistician, associate professor $^{1}$, Christian Mølgaard associate professor ${ }^{1}$, Kim F Michaelsen professor ${ }^{1}$, Dilnesaw Zerfu associate researcher ${ }^{7}$, Søren Brage researcher ${ }^{8}$, Åse B Andersen professor ${ }^{9}$, Henrik Friis professor ${ }^{1}$

${ }^{1}$ Department of Nutrition, Exercise and Sports, University of Copenhagen, Rolighedsvej 30, 1958 Frederiksberg C, Denmark; ${ }^{2}$ Department of Laboratory Sciences and Pathology, Jimma University, Jimma, Ethiopia; ${ }^{3}$ Department of Psychiatry, College of Public Health and Medical Sciences, Jimma University, Jimma, Ethiopia; ${ }^{4}$ Department of Internal Medicine, Jimma University Specialized Hospital, Jimma, Ethiopia; ${ }^{5}$ Department of Paediatric and Child Health, Jimma University Specialized Hospital, Jimma, Ethiopia; ${ }^{6}$ Childhood Nutrition Research Centre, UCL Institute of Child Health, London, UK; ${ }^{7}$ Ethiopian Health and Nutrition Research Institute, Addis Ababa, Ethiopia; ${ }^{8} \mathrm{MRC}$ Epidemiology Unit, University of Cambridge, Cambridge, UK; ${ }^{9}$ Department of Infectious Diseases, Odense University Hospital, Odense, Denmark
\end{abstract}

\begin{abstract}
Objectives To determine the effects of lipid based nutritional supplements with either whey or soy protein in patients with HIV during the first three months of antiretroviral treatment (ART) and to explore effects of timing by comparing supplementation at the start of ART and after three months delay.

Design Randomised controlled trial.

Setting Three public ART facilities in Jimma, Oromia region, Ethiopia. Participants Adults with HIV eligible for ART with body mass index (BMI) $>16$.

Intervention Daily supplementation with $200 \mathrm{~g}$ (4600 kJ) of supplement containing whey or soy during either the first three or the subsequent three months of ART.

Outcome measures Primary: lean body mass assessed with deuterium dilution, grip strength measured with dynamometers, and physical activity measured with accelerometer and heart rate monitors. Secondary: viral load and CD4 counts. Auxiliary: weight and CD3 and CD8 counts.

Results Of 318 patients enrolled, 210 (66\%) were women, mean age was 33 (SD 9), and mean BMI was 19.5 (SD 2.4). At three months, participants receiving the supplements containing whey or soy had increased their lean body mass by $0.85 \mathrm{~kg}$ (95\% confidence interval $0.16 \mathrm{~kg}$ to $1.53 \mathrm{~kg})$ and $0.97 \mathrm{~kg}(0.29 \mathrm{~kg}$ to $1.64 \mathrm{~kg})$, respectively, more than controls. This was accompanied by an increased gain of grip strength of $0.68 \mathrm{~kg}(-0.11 \mathrm{~kg}$ to $1.46 \mathrm{~kg})$ for the whey supplement group and $0.93 \mathrm{~kg}(0.16 \mathrm{~kg}$ to $1.70 \mathrm{~kg})$ for the soy supplement group. There
\end{abstract}

were no effects on physical activity. Total weight gain increased by 2.05 $\mathrm{kg}(1.12 \mathrm{~kg}$ to $2.99 \mathrm{~kg})$ and $2.06 \mathrm{~kg}(1.14 \mathrm{~kg}$ to $2.97 \mathrm{~kg})$ for the whey and soy groups, respectively. In addition, in the whey supplement group overall CD3 counts improved by 150 cells/ $\mu \mathrm{L}$ ( 24 to 275 cells $/ \mu \mathrm{L}$ ), of which 112 cells $/ \mu \mathrm{L}$ (15 to 209 cells $/ \mu \mathrm{L}$ ) were CD8 and 25 cells $/ \mu \mathrm{L}$ ( -2 to 53 cells/ $\mu \mathrm{L}$ ) were CD4. Effects of the soy containing supplement on immune recovery were not significant. The effects of the two supplements, however, were not significantly different in direct comparison. Exploratory analysis showed that relatively more lean body mass was gained by patients with undetectable viral load at three months. Patients receiving delayed supplementation had higher weight gain but lower gains in functional outcomes.

Conclusions Lipid based nutritional supplements improved gain of weight, lean body mass, and grip strength in patients with HIV starting ART. Supplements containing whey were associated with improved immune recovery.

Trial registration Controlled-trials.com ISRCTN32453477.

\section{Introduction}

Access to antiretroviral treatment (ART) has improved substantially in sub Saharan Africa over the past decade, but high rates of mortality are still reported, especially in the first few months of treatment. ${ }^{1}$ Poor nutritional status at start of ART has been identified as a predictor of mortality independent of immune status, ${ }^{2-4}$ while patients who gain weight in the early phase of treatment have improved prognosis. ${ }^{5-9}$ Nutritional 
support is becoming an integral part of ART programmes in African countries, and various supplements are now widely distributed. ${ }^{10}{ }^{11}$ At present, however, there is little evidence on the effects of supplementation. ${ }^{12}$ Information is urgently needed to guide supplementation programmes towards optimal composition and timing as well as identification of individuals most likely to benefit.

Loss of lean body mass, in particular, has been associated with mortality in patients with HIV. ${ }^{13-17}$ In addition, low lean body mass results in functional limitations, ${ }^{18-20}$ which can have devastating consequences for patients and their families. Maintenance of work capacity and an adequate level of activity is essential to sustain everyday functioning and protect patients' livelihoods. ${ }^{21}$ It has been suggested that whey protein can improve the recovery of lean body mass in patients with HIV, ${ }^{22}$ but this has not yet been confirmed by empirical research. ${ }^{23}{ }^{24}$ Furthermore, whey might also have an immune modulating effect as it increases plasma glutathione, an important antioxidant often deficient in those with HIV..$^{25-27}$ This was supported by a recent study showing that supplementation with $40 \mathrm{~g}$ of whey a day was associated with increased CD4 counts. ${ }^{28}$ We conducted a randomised controlled trial among patients with HIV who were starting ART in Ethiopia to investigate the effects of a lipid based nutrient supplement containing whey or soy protein in the first three months of treatment compared with a control group of patients who started ART without nutrient supplements. Primary outcomes were lean body mass, grip strength, and expenditure of energy on physical activity. Secondary outcomes were HIV viral load and CD4 counts, while auxiliary outcomes included weight and CD8 and CD3 counts. The control group received delayed supplementation during the subsequent three months of ART, which allowed us to explore potential effects of timing in supplementation.

\section{Methods \\ Study design}

The ART food study was a randomised controlled trial, with randomisation stratified by body mass index (BMI). Participants with BMI $>17$ were allocated $(1: 1: 1)$ to early supplementation with a supplement containing whey (group 1), early supplementation with a supplement containing soy (group 2), or delayed supplementation with either the whey or soy supplement (group 3a+b). Participants with BMI 16-17 were allocated (1:1) to early supplementation with whey (group 4) or early supplementation with soy (group 5) (fig $1 \Downarrow$ ).

The study was designed to assess three main comparisons at three months' follow-up: whey containing supplement versus no supplement, soy containing supplement versus no supplement, and whey versus soy containing supplements. The first two comparisons were conducted in participants with BMI $>17$, as the delayed supplementation groups served as controls. The third comparison was conducted among all participants with $\mathrm{BMI}>16$, as groups with BMI 16-17 and BMI $>17$ were merged for this analysis (group $1+4 v$ group $2+5$ ). Secondly, we compared early and delayed supplementation in participants with BMI $>17$ to investigate potential effects of timing in supplementation (group $1+2 v$ group $3 a+3 b$ ).

\section{Participants}

Patients eligible for ART at Jimma University Specialized Hospital, Jimma Health Centre, and Agaro Health Centre were invited to participate if they were aged $\geq 18$, had a BMI $\geq 16$, and lived within $50 \mathrm{~km}$ of the recruitment site. Exclusion criteria were pregnancy, lactation, known diabetes, or current use of nutritional supplements. ART was initiated if CD4 counts were $\leq 200$ cells $/ \mu \mathrm{L}$ irrespective of clinical symptoms, if CD4 counts were $\leq 350$ cells $/ \mu \mathrm{L}$ in those classed as WHO clinical stage III, or if patients were classed as WHO clinical stage IV irrespective of CD4 count. ${ }^{29}$ The preferred ART regimen consisted of lamivudine with tenofovir or zidovudine, and efavirenz or nevirapine. Patients were given co-trimoxazole prophylaxis and nutritional counselling according to national guidelines. ${ }^{29}{ }^{30}$

\section{Nutritional intervention}

Participants received $200 \mathrm{~g}$ supplement (about $4600 \mathrm{~kJ}$ ) a day for three months during either the first three months (early) or the subsequent three months of ART (delayed). The supplements were developed by Nutriset (Malaunay, France), based on Plumpy'Sup, with $32 \mathrm{~g}$ of either whey protein concentrate $80 \%$ or soy protein isolate. In both supplements, energy distribution was $60 \%$ fat, $24 \%$ carbohydrates, and $16 \%$ protein. The daily ration contained two recommended nutrient intakes of vitamins, zinc, selenium, and copper, and one intake of other minerals ${ }^{31}$ (table $1 \Downarrow$ ). Patients were instructed in using the supplement and allowed to try it for two days before study enrolment.

Supplements were provided monthly in $100 \mathrm{~g}$ sachets, and adherence was assessed from returned sachets and self reported consumption. Furthermore, a qualitative study was conducted to investigate the use, perceptions, and acceptability of the supplement (reported in detail elsewhere ${ }^{32}$ ).

\section{Data collection}

Trained study staff collected data on all outcomes in local languages at baseline and at three and six months' follow-up. In addition, weight and CD 4 counts were measured at 12 months' follow-up to assess post-trial differences between early and delayed intervention. Demographic data were collected at baseline with a structured questionnaire. Height and weight were measured with calibrated scales and stadiometers, respectively. Energy intake was assessed from a 24 hour food recall, with a pre-coded chart and a recall kit with household utensils and models of Ethiopian dishes, standard recipes, and local food composition tables. ${ }^{33}{ }^{34}$ Information regarding WHO clinical stage of HIV was extracted from routine patient records and checked by a study clinician.

\section{Primary outcomes}

The primary outcomes were lean body mass, grip strength, and expenditure of energy on physical activity. Body composition was assessed with $30 \mathrm{~g}$ deuterium oxide $\left(99.8 \%{ }^{2} \mathrm{H}\right.$, Sercon, Crewe, UK) weighed with $0.01 \mathrm{~g}$ precision and given orally after collection of pre-dose saliva samples. ${ }^{35}$ Post-dose saliva samples were collected after four hours' equilibration. Saliva enrichment of deuterium was determined by Fourier Transform Infrared Spectrometer (IRAffinity-1, Shimadzu, Kyoto, Japan). Total body water was calculated from post-dose deuterium enrichment with adjustment for pre-dose enrichment, using a factor of 1.041 to adjust for proton exchange. Lean body mass was calculated based on an assumed hydration factor of $73.2 \% .^{35}$ Grip strength was determined twice each for the right and left hand alternately with a digital dynamometer (Takei Scientific Instruments Co, Niigata, Japan). The mean of the highest value for the right and left hand was recorded. This procedure was then repeated and the highest value used for analyses.

Expenditure of on energy physical activity was measured with a combined uniaxial accelerometer and heart rate sensor (Actiheart, CamNtech, Cambridge, UK), as described 
elsewhere. ${ }^{36}$ For logistical reasons we assessed physical activity only in participants from Jimma University Specialized Hospital and Jimma Health Centre. Heart rate was calibrated with a 250 $\mathrm{m}$ self paced walk test followed by a two minute recovery period. The monitor was worn continuously over four days, with data collected every 15 seconds. Physical activity energy expenditure was modelled with branched equations. ${ }^{37}$ The estimation of intensity of activity was determined with group calibration equations for both accelerometry and heart rate..$^{38}$ We included in the analyses those individual recordings with $\geq 24$ hours of valid data.

\section{Secondary and auxiliary outcomes}

Secondary outcomes included viral load and CD4 counts, and auxiliary outcomes included weight and CD3 and CD8 counts. Viral load (HIV-1 RNA) was determined from plasma, which was kept at $-80^{\circ} \mathrm{C}$, with a commercial real time PCR

(polymerase chain reaction) assay with automated extraction of RNA (RealTime HIV-1, Abbott Molecular, Abbott Laboratories, IL). CD3, CD4, and CD8 counts were determined with flow cytometry (Fascount, Becton Dickinson, San José, CA).

\section{Randomisation and blinding}

The two supplement types were labelled with three codes each, which were kept in sealed envelopes until trial completion. Two stratified blocked randomisation sequences were prepared by HF for BMI 16-17 and BMI <17 in blocks of 18 with www. randomization.com. The study was fully blinded regarding comparison of the two supplements, which were similar in taste and texture, while it was blinded only for outcome assessors and data analysts regarding the comparisons of early and delayed supplementation groups. A designated person, not involved in recruitment or data collection, had sole access to the random sequence lists and was responsible for supplement allocation.

\section{Sample size calculation}

The study's sample size was calculated to detect differences in lean body mass. A previous study had found that lipid based nutrient supplementation resulted in an increase of lean body mass of $0.5 \mathrm{SD}$ of the baseline distribution among HIV patients. ${ }^{39}$ As we expected only a modest gain in lean body mass in the unsupplemented control group, we expected the difference between groups to be around $0.4 \mathrm{SD}$. We calculated that 100 participants in each group (that is, early whey supplement, early soy supplement, and delayed supplement) would allow us to detect a 0.4 SD difference in lean body mass with $80 \%$ power and $5 \%$ significance level. To allow for $15 \%$ loss to follow-up, we planned to recruit 350 patients. We used data on the BMI distribution of patients starting ART at the hospital in Jimma during the previous year to estimate the expected relative group sizes. Based on this, we expected that from 400 patients eligible for ART, 300 would have BMI > 17, 50 would have BMI 16-17, and 50 would have $\mathrm{BMI}<16$. To recruit this number of patients, we anticipated a 16 month inclusion period at Jimma University Specialized Hospital. Because of an increasing number of ART facilities in the study area, however, the number of eligible patients at the hospital declined. Consequently, we decided to include health centres in Jimma and Agaro as recruitment sites and extend the inclusion period. After 26 months (August 2012), we had included a total of 318 participants and as attrition was lower than anticipated, we estimated that we had reached an adequate sample size.

\section{Data analyses}

All data were double entered and validated with EpiData (EpiData Association, Odense, Denmark) and analysed with STATA/IC version 11.2 (StataCorp LP, College Station, TX). All analyses were done by the intention to treat principle. Associations with $\mathrm{P}$ values $<0.05$ were considered significant. We considered both unadjusted models, which included only the supplementation groups and baseline adjustment, and adjusted models, which included age, sex, and education level for all outcomes, and height for lean body mass and weight. The comparisons between supplementation groups at three months' follow-up were carried out with analysis of covariance models. The comparison of early and delayed supplementation at six and 12 months' follow-up was carried out with linear mixed models based on all available repeated measurements. These models included interactions between supplementation and time and participant specific random effects to capture the serial correlation in the repeated measurements within each participant. Outcomes were log transformed when appropriate. We also carried out exploratory analyses to investigate interactions between supplementation groups and selected variables, including sex, age group $(<40$ or $\geq 40)$, BMI $(<18.5$ or $\geq 18.5)$, CD4 counts at baseline ( $<200$ or $\geq 200$ cells $/ \mu \mathrm{L})$, and viral load at three month' follow-up ( 0 copies $/ \mathrm{mL}$ or $>0$ copies/ml), to explore potential differential effects of supplementation between subgroups of participants.

\section{Results}

A total of 453 patients were screened between July 2010 and August 2012 (fig $2 \Downarrow$ ). Of these, $318(70 \%)$ were enrolled and 135 were not eligible because their BMI was $<16(7 \%)$ or they declined (23\%). Of the enrolled participants, $281(88 \%)$ completed three months' follow-up and $273(86 \%)$ completed six months' follow-up. Table $2 \Downarrow$ presents the baseline characteristics of participants with BMI $>17(n=282)$. We found no major differences between the three intervention groups. Furthermore, the two early supplementation groups remained similar when we included participants with BMI 16-17 ( $n=36$, data not shown).

Of 318 enrolled participants, $210(66 \%)$ were women, the mean age was 33 (SD 9), and the mean BMI was 19.5 (SD 2.4). The median adherence to the supplement was $88 \%$ (interquartile range $73-96 \%$ ). There was no difference in adherence to the two supplements, but adherence was lower during early supplementation than delayed supplementation $(86 \%$ (interquartile range $71-95 \%) v 93 \%(76-97 \%), \mathrm{P}=0.01)$. Eighty one $(28 \%)$ had "poor adherence," which was defined as intake $<75 \%$. This was supported by self reported consumption data (not shown).

\section{Early supplementation}

Table $3 \Downarrow$ presents differences between groups at three months' follow-up among participants with BMI $>17(n=282)$.

Participants receiving the whey and soy supplements had gained $0.85 \mathrm{~kg}(95 \%$ confidence interval $0.16 \mathrm{~kg}$ to $1.53 \mathrm{~kg}$ ) and 0.97 $\mathrm{kg}(0.29 \mathrm{~kg}$ to $1.64 \mathrm{~kg})$ lean body mass, respectively, more than controls. This was accompanied by a borderline significant effect on grip strength of $0.68 \mathrm{~kg}(-0.11 \mathrm{~kg}$ to $1.46 \mathrm{~kg})$ for the whey supplement and an effect of $0.93 \mathrm{~kg}(0.16 \mathrm{~kg}$ to $1.70 \mathrm{~kg})$ for the soy supplement. Differences in increases of energy expenditure on physical activity were not significant at $6 \%(-13$ to $29 \%$ ) and $10 \%$ (-9 to $33 \%$ ) for whey and soy supplements, respectively (total $n=98$ ). The total weight gain in participants receiving whey and soy supplements was $2.05 \mathrm{~kg}(1.12 \mathrm{~kg}$ to 
$2.99 \mathrm{~kg})$ and $2.06 \mathrm{~kg}(1.14 \mathrm{~kg}$ to $2.97 \mathrm{~kg})$ higher than unsupplemented controls. In comparison, participants who started ART without nutritional supplementation had a total weight gain of only $0.87 \mathrm{~kg}(0.22 \mathrm{~kg}$ to $1.52 \mathrm{~kg}) \mathrm{kg}$, with no gain in lean body mass $(0.06 \mathrm{~kg},-0.43 \mathrm{~kg}$ to $0.55 \mathrm{~kg})$ and no significant improvement in grip strength $(0.47 \mathrm{~kg},-0.09 \mathrm{~kg}$ to $1.04 \mathrm{~kg}$ ).

Though we found no differences in suppression of viral load between groups, overall CD3 counts increased by 150 cells/ $\mu \mathrm{L}$ ( $95 \%$ confidence interval 24 to 275 cells $/ \mu \mathrm{L}$ ) in the whey supplement group compared with controls. The increase was 112 cells $/ \mu \mathrm{L}$ ( 15 to 209 cells $/ \mu \mathrm{L}$ ) for CD8 counts, 25 cells $/ \mu \mathrm{L}$ ( -2 to 53 cells $/ \mu \mathrm{L}$ ) for CD4 counts, which was of borderline significance. Effects on immune recovery were not significant for the soy supplement. The effects of the two supplements, however, did not differ significantly, when we compared them directly among participants with BMI $>17$ (data not shown).

There were no differences in ART regimens or adherence to supplementation between groups. The main ART regimen was tenofovir/lamivudine/efavirenz, which was received by 65 (70\%, early whey supplement), 73 (80\%, early soy supplement), and 63 (68\%, delayed supplement). Self reported adherence to ART was $>95 \%$, with no difference between groups. Furthermore, the effects of supplementation were not modified by baseline BMI, sex, age, or CD4 count for any of the outcomes. At three months' follow-up, viral load had become undetectable in 81 (33\%) participants with baseline BMI $>17$. Among these participants, supplementation was associated with an increase in lean body mass of $1.76 \mathrm{~kg}$ (95\% confidence interval $0.79 \mathrm{~kg}$ to $2.74 \mathrm{~kg}$ ). There was no significant gain in lean body mass among participants who still had detectable virus after three months of ART $(0.42 \mathrm{~kg},-0.37 \mathrm{~kg}$ to $1.20 \mathrm{~kg}$; interaction $\mathrm{P}=0.03$ ).

Table $4 \Downarrow$ shows that there were no significant differences between effects of the two supplements during early supplementation in patients with BMI $>16$ when we combined the BMI groups $(\mathrm{n}=225)$.

\section{Timing of supplementation}

Table $5 \Downarrow$ shows differences at six months' follow-up between groups allocated to early and delayed supplementation (BMI $>17, \mathrm{n}=282$ ). There was no difference in gain in lean body mass, but participants who received delayed supplementation had a smaller increase in grip strength than those receiving early supplementation $(-0.84 \mathrm{~kg}, 95 \%$ confidence interval $-1.53 \mathrm{~kg}$ to $-0.04 \mathrm{~kg}$ ). Similarly, the comparison showed that increase in physical activity was lower in participants with delayed supplementation $(-22 \%,-35 \%$ to $-5 \%)$. Those receiving delayed supplementation, however, had a $1.20 \mathrm{~kg}(0.32 \mathrm{~kg}$ to $2.09 \mathrm{~kg}$ ) higher gain of total body weight from baseline to six months than those receiving early supplementation. Adjustment for differences in adherence only partially explained this difference in weight gain (adjusted estimate $0.99 \mathrm{~kg}, 0.08 \mathrm{~kg}$ to $1.89 \mathrm{~kg}$ ). We found no differences in energy intake from usual diet between groups at either three or six months' follow-up $(\mathrm{P}>0.69)$. Finally, we found that changes in viral load and immune recovery did not depend on timing.

Figure $3 \Downarrow$ shows unadjusted mean differences in primary and secondary outcomes at three and six months' follow-up in intervention groups. Participants who received early supplementation subsequently lost some of the weight gained during supplementation. The weight loss consisted of fat mass only, however, as there was a continued gain of lean body mass after supplementation had ended. Furthermore, the figure shows that differences in grip strength at three months were sustained at six months, while differences in CD4 counts were not.

Post-trial data from 12 months' follow-up (BMI >17, n=230) showed that the differences in weight gain between the early and delayed supplementation groups were not sustained. Furthermore, there was no difference between increases in CD4 counts in early and delayed supplementation groups (data not shown).

\section{Discussion \\ Principal findings}

Provision of lipid based supplements in the first three months of ART improved gains in weight, lean body mass, and grip strength among patients with HIV and BMI $>17$. The effects of supplementation were considerable, resulting in a more than threefold weight gain compared with the effects of starting ART alone and with substantially more lean body mass gained. Supplementation improved grip strength but had no significant effects on physical activity. Complete data on physical activity, however, were obtained for only a small number of participants because assessment was possible at only two of the three centres, and many participants declined monitoring of physical activity because of the additional study visit it involved. As physical activity is a behavioural outcome with high variability, we did not have sufficient power to detect potential differences between groups. Furthermore, the whey supplement had effects on immune recovery. The changes in CD8, CD3, and CD4 counts were not associated with differences in viral load suppression, which was similar in all groups. We found no differences between the two supplements in participants with BMI $>17$ or all participants with $\mathrm{BMI}>16$.

\section{Strengths and limitations of study}

The main strength of this study is its randomised controlled design, making it the first study to investigate the effects of lipid based nutrient supplements and ART compared with ART alone. The study was not powered to detect differences in mortality, but detailed data on body composition, functional outcomes, viral load, and immune recovery strengthened the evaluation of supplementation effects. The study was limited by its exclusion of patients with $\mathrm{BMI}<16$ and by including only patients with BMI $>17$ in the comparison between supplemented and unsupplemented groups. The associations between weight gain and improved clinical outcomes, however, have previously been observed across all BMI groups, ${ }^{78}$ and, in line with this, we found that the effect of supplementation was not modified by baseline BMI. Finally, the validity of the deuterium dilution technique hinges on an assumption about lean tissue hydration, which has been questioned in patients with HIV. ${ }^{41}$ As both HIV and malnutrition are associated with expansion of the extracellular water compartment, a reduction in extracellular water towards normal during ART and nutritional supplementation would potentially cause an underestimation of gains in lean body mass. We expect these changes to be of minor importance in the patients with BMI $>17$ included in the present analysis.

\section{Comparison with other studies}

The clinical relevance of weight gain after initiation of ART is well described but mainly in observational studies, ${ }^{7-9}$ when it might just be a marker of individual clinical response. There are few data describing weight gain induced by nutritional supplementation. A recent Cochrane review ${ }^{12}$ included data 
from an unpublished trial in Kenya, showing that three months of fortified blended food compared with no supplement resulted in a weight gain of $1.12 \mathrm{~kg}$ ( $95 \%$ confidence interval $0.29 \mathrm{~kg}$ to $1.95 \mathrm{~kg}$ ) among malnourished patients with HIV receiving ART, which is notably less than the effect seen in the present study. Although the study populations are not directly comparable, the smaller effect could be related to differences in supplement use, energy density, or nutrient quality. Lipid based nutrient supplements have previously been associated with higher weight gains than fortified blended foods. ${ }^{39}$

Effects on immune recovery were seen only for the whey containing supplement in comparisons with unsupplemented participants. We found no significant difference in the direct comparison of the two supplements. Both of the protein sources used in this study were of high quality. Soy isolate contains $>90 \%$ protein, no anti-nutrients, and a high amount of glutamine, which could have positive effects similar to those suggested for whey. ${ }^{42-44}$ Additional studies are needed to determine whether soy proteins can be used with similar effects to dairy based proteins in supplementation of HIV patients, as this could reduce programme costs.

Our inclusion of a delayed intervention group allowed us to explore effects of timing as part of post hoc analyses. Little is known about the optimal timing of nutritional supplementation. A study in Zambia suggested that metabolic derangements similar to the re-feeding syndrome might explain some of the increased mortality among malnourished patients with HIV starting ART. ${ }^{45} 46$ Thus, it might be beneficial to postpone nutritional supplementation until inflammation has faded and the patient has been stabilised. We have previously reported that participants' consumption of the supplement was reduced in the first few weeks after ART initiation. ${ }^{32}$ This study confirmed that adherence was lower during early supplementation than during delayed supplementation, but the difference in adherence only partially explained a higher weight gain observed for delayed supplementation. The comparison of outcomes at six months, however, should be interpreted with caution as some of the weight gained during supplementation might be lost subsequently, as seen after the end of early supplementation. In fact, data at 12 months showed that the weight difference was not sustained six months after the trial had ended. We also found that patients who had undetectable viral load three months after ART initiation had gained more lean body mass than patients with a poorer response to treatment. In line with this, a previous study found that therapeutic re-feeding resulted in gain of fat mass rather than lean body mass if patients had systemic infection. ${ }^{47}$ Although causality cannot be determined from these findings, they indicate that patients might better use nutrients for synthesis of lean tissue after inflammation has declined, which could be an argument for delaying supplementation. Functional outcomes, however, improved mainly during early supplementation. Inclusion of groups initiating supplementation at various time points in relation to ART, measurement of inflammatory markers, and patients' appetite would enable further investigation of the optimal timing of supplementation.

\section{Conclusions and implications}

We tested the effect of a rather short duration (three months) of nutritional supplementation, while many of the current supplementation programmes provide similar supplements for up to six months. After this study ended, Ethiopia implemented guidelines for nutritional supplementation of all patients with HIV with BMI $<18.5$ for up to six months. A recent evaluation report showed that the programme is costly and challenging, with more than $70 \%$ of patients defaulting from supplementation. ${ }^{48}$ In addition, lipid based nutrient supplements are energy dense and high fat, and, while this is beneficial for maintaining an adequate energy intake, long term supplementation could increase the risk of metabolic complications in general and in particular in patients receiving ART. ${ }^{49}$ Providing time limited supplementation involves less risk of metabolic complications and is less resource demanding.

We have shown that three months' lipid based nutrient supplementation at the start of ART improved weight, lean body mass, and grip strength. In addition, the whey containing supplement supported immune recovery. The role of timing and type of protein source in the supplement merits further investigation. We have previously shown that supplementation was feasible and acceptable in the study setting. ${ }^{32}$ It is now important to investigate how barriers to large scale supplementation can be overcome to achieve effectiveness of nutritional supplementation for patients with HIV.

We thank the participants, study team, and staff at the ART clinics at Jimma University Specialized Hospital, Jimma Health Centre, and Agaro Health Centre.

Contributors: MFO, AA, PK, CM, KFM, ABA, and HF conceptualised and designed the study. MFO, AA, PK, MT, DY, TG, DZ, and SB contributed to the acquisition of data. Data were analysed by MFO with the assistance of CR. MFO, AA, PK, JW, SB, ABA, and HF contributed to the interpretation of results. MFO drafted the manuscript, and all co-authors contributed to reviewing the manuscript. HF is guarantor.

Funding: The study was funded by US Dairy Export Council, International Atomic Energy Agency (IAEA), and Ministry of Foreign Affairs of Denmark (DANIDA). Nutriset developed the supplements and partially covered transportation expenses. The funders had no role in study design, data collection, and analysis, the decision to publish or preparation of the manuscript

Competing interests: All authors have completed the ICMJE uniform disclosure form at www.icmje.org/coi_disclosure.pdf and declare: no support from any organisation for the submitted work; no financial relationships with any organisations that might have an interest in the submitted work in the previous three years; no other relationships or activities that could appear to have influenced the submitted work.

Ethical approval: The study was approved by the Ethiopian National Health Research ethical review committee (RDHE/30-90/2009), and trial authorisation was obtained from the Food, Medicine and Health Care Administration and Control Authority of Ethiopia (02/6/05/50), while a consultative approval was given by the Danish national committee on biomedical research ethics. Written informed consent was obtained from all participants. Study visits were coordinated with routine visits for ART care and transportation costs were reimbursed for additional visits. A data safety and monitoring board assessed interim reports during the trial.

Data sharing: Additional data available on request from the corresponding author.

Transparency: The lead authors (MRO and AA) affirm that this manuscript is an honest, accurate, and transparent account of the study being reported; that no important aspects of the study have been omitted; and that any discrepancies from the study as planned (and, if relevant, registered) have been explained.

1 Braitstein P, Brinkhof MWG, Dabis F, Schechter M, Boulle A, Miotti P, et al. Mortality of HIV-1-infected patients in the first year of antiretroviral therapy: comparison between low-income and high-income countries. Lancet 2006;367:817-24.

2 Lawn SD, Harries AD, Anglaret X, Myer L, Wood R. Early mortality among adults accessing antiretroviral treatment programmes in sub-Saharan Africa. AIDS 2008;22:1897-908.

3 May M, Boulle A, Phiri S, Messou E, Myer L, Wood R, et al. Prognosis of patients with HIV-1 infection starting antiretroviral therapy in sub-Saharan Africa: a collaborative analysis of scale-up programmes. Lancet 2010;376:449-57. 


\section{What is already known on this topic}

In patients with HIV, poor nutritional status in terms of low BMI at the start of antiretroviral treatment (ART) is associated with poor treatment outcomes

Various nutritional supplements are widely distributed as part of ART programmes in sub Saharan Africa, but little is known about the effects of these resource demanding programmes

\section{What this study adds}

Three months' supplementation with a lipid based nutrient supplement containing either whey or soy protein resulted in a more than threefold weight gain compared with ART alone. Substantially more lean body mass was gained and grip strength was improved by supplementation

Supplements containing whey protein were also associated with improved immune recovery

Differences in effects relating to protein type and timing of supplementation merit further investigation

4 Gupta A, Nadkarni G, Yang W-T, Chandrasekhar A, Gupte N, Bisson GP, et al. Early mortality in adults initiating antiretroviral therapy (ART) in low- and middle-income countries (LMIC): a systematic review and meta-analysis. PLoS One 2011;6:e28691

5 Malvy D, Thiébaut R, Marimoutou C, Dabis F. Weight loss and body mass index as predictors of hiv disease progression to AIDS in adults. Aquitaine Cohort, France, predictors of hiv disease progression to AlDS

6 Tang AM, Jacobson DL, Spiegelman D, Knox TA, Wanke C. Increasing risk of $5 \%$ or greater unintentional weight loss in a cohort of HIV-infected patients, 1995 to 2003. J Acquir Immune Defic Syndr 2005;40:70-6.

7 Madec Y, Szumilin E, Genevier C, Ferradini L, Balkan S, Pujades M, et al. Weight gain at 3 months of antiretroviral therapy is strongly associated with survival: evidence from two developing countries. AIDS 2009;23:853-61.

8 Koethe JR, Lukusa A, Giganti MJ, Chi BH, Nyirenda CK, Limbada MI, et al. Association between weight gain and clinical outcomes among malnourished adults initiating antiretroviral therapy in Lusaka, Zambia. J Acquir Immune Defic Syndr 2010;53:507-13.

9 Sudfeld CR, Isanaka S, Mugusi FM, Aboud S, Wang M, Chalamilla GE, et al. Weight change at $1 \mathrm{mo}$ of antiretroviral therapy and its association with subsequent mortality, morbidity, and CD4 T cell reconstitution in a Tanzanian HIV-infected adult cohort. Am J Clin Nutr 2013;97:1278-87.

10 Lamb MR, El-Sadr WM, Geng E, Nash D. Association of adherence support and outreach services with total attrition, loss to follow-up, and death among ART patients in sub-Saharan Africa. PLoS One 2012;7:e38443.

11 Anema A, Zhang W, Wu Y, Elul B, Weiser SD, Hogg RS, et al. Availability of nutritional support services in HIV care and treatment sites in sub-Saharan African countries. Public Health Nutr 2012;15:938-47

12 Grobler L, Siegfried N, Visser ME, Mahlungulu SSN, Volmink J. Nutritional interventions for reducing morbidity and mortality in people with HIV. Cochrane Database Syst Rev 2013;2:CD004536

13 Melchior JC, Niyongabo T, Henzel D, Durack-Bown I, Henri SC, Boulier A. Malnutrition and wasting, immunodepression, and chronic inflammation as independent predictors of survival in HIV-infected patients. Nutrition 1999;15:865-9.

14 Kotler DP, Tierney AR, Wang J, Pierson RN Jr. Magnitude of body-cell-mass depletion and the timing of death from wasting in AIDS. Am J Clin Nutr 1989;50:444-7.

15 Süttmann U, Ockenga J, Selberg O, Hoogestraat L, Deicher H, Müller MJ. Incidence and prognostic value of malnutrition and wasting in human immunodeficiency virus-infected outpatients. J Acquir Immune Defic Syndr Hum Retrovirol 1995;8:239-46.

16 Ott M, Fischer H, Polat H, Helm EB, Frenz M, Caspary WF, et al. Bioelectrical impedance analysis as a predictor of survival in patients with human immunodeficiency virus infection. $J$ Acquir Immune Defic Syndr Hum Retrovirol 1995;9:20-5.

17 Schwenk A, Beisenherz A, Römer K, Kremer G, Salzberger B, Elia M. Phase angle from bioelectrical impedance analysis remains an independent predictive marker in HIV-infected patients in the era of highly active antiretroviral treatment. Am J Clin Nutr 2000;72:496-501.

18 Kusko RL, Banerjee C, Long KK, Darcy A, Otis J, Sebastiani P, et al. Premature expression of a muscle fibrosis axis in chronic HIV infection. Skeletal Muscle 2012;2:10.

19 Desquilbet L, Jacobson LP, Fried LP, Phair JP, Jamieson BD, Holloway M, et al. HIV-1 infection is associated with an earlier occurrence of a phenotype related to frailty. $J$ Gerontol A Biol Sci Med Sci 2007;62:1279-86.

20 Raso V, Shephard RJ, do Rosário Casseb JS, da Silva Duarte AJ, D 7 Andréa Greve JM. Handgrip force offers a measure of physical function in individuals living with HIV/AIDS. $J$ Acquir Immune Defic Syndr 2013;63:e30-2.

21 Gillespie SR. AIDS, poverty, and hunger. International Food Policy Res Inst (IFPRI), 2006. http://dx.doi.org/10.2499/0896297586BK

22 Hoppe C, Andersen GS, Jacobsen S, Mølgaard C, Friis H, Sangild PT, et al. The use of whey or skimmed milk powder in fortified blended foods for vulnerable groups. $J$ Nutr 2008;138:145-61S.

23 Agin D, Kotler DP, Papandreou D, Liss M, Wang J, Thornton J, et al. Effects of whey protein and resistance exercise on body composition and muscle strength in women with HIV infection. Ann N Y Acad Sci 2000;904:607-9.

24 Agin D, Gallagher D, Wang J, Heymsfield SB, Pierson RN, Kotler DP. Effects of whey protein and resistance exercise on body cell mass, muscle strength, and quality of life in women with HIV. AIDS 2001:15:2431-40.

25 Bounous G, Baruchel S, Falutz J, Gold P. Whey proteins as a food supplement in HIV-seropositive individuals. Clin Invest Med 1993;16:204-9.

26 Micke P, Beeh KM, Schlaak JF, Buhl R. Oral supplementation with whey proteins increases plasma glutathione levels of HIV-infected patients. Eur J Clin Invest 2001;31:171-8.

27 Micke P, Beeh KM, Buhl R. Effects of long-term supplementation with whey proteins on plasma glutathione levels of HIV-infected patients. Eur J Nutr 2002;41:12-8.

28 Sattler FR, Rajicic N, Mulligan K, Yarasheski KE, Koletar SL, Zolopa A, et al. Evaluation of high-protein supplementation in weight-stable HIV-positive subjects with a history of weight loss: a randomized, double-blind, multicenter trial. Am J Clin Nutr 2008;88:1313-21.
29 Federal HIV/AIDS Prevention and Control Office. Guidelines for management of opportunistic infections and anti retroviral treatment in adolescents and adults in Ethiopia. Federal Ministry of Health, Ethiopia, 2008.

30 Federal Ministry of Health. National guideline for nutritional care and support for PLHIV. Federal Democratic Republic of Ethiopia Ministry of Health, 2011. www.ilo.org/wcmsp5/ groups/public/---ed_protect/---protrav/---ilo_aids/documents/legaldocument/wcms_125388. pdf

$31 \mathrm{FAO} / \mathrm{WHO}$. Human vitamin and mineral requirements. Report of a joint FAO/WHO expert consultation, Bangkok, Thailand. Food and Nutrition Division FAO, 2001.

32 Olsen M, Tesfaye, Kæstel, Friis, Holm. Use, perceptions, and acceptability of a ready-to-use supplementary food among adult HIV patients initiating antiretroviral treatment: a qualitative study in Ethiopia. Patient Prefer Adherence 2013;7:481-8.

33 EHNRI, FAO. Food composition table for use in Ethiopia. Ethiopian Health and Nutrition Research Institute, 1998

34 Ethiopian Nutrition Institute. Ethiopian traditional recipes. Ministry of Health, 1980.

35 IAEA human health series. Introduction to body composition assessment using the deuterium dilution technique with analysis of saliva samples by Fourier transform infrared spectrometry. International Atomic Energy Agency, 2010.

36 Brage S, Brage N, Franks PW, Ekelund U, Wareham NJ. Reliability and validity of the combined heart rate and movement sensor Actiheart. Eur J Clin Nutr 2005;59:561-70.

37 Brage S, Brage N, Franks PW, Ekelund U, Wong M-Y, Andersen LB, et al. Branched equation modeling of simultaneous accelerometry and heart rate monitoring improves estimate of directly measured physical activity energy expenditure. J Appl Physiol 2004:96:343-51.

38 Christensen DL, Faurholt-Jepsen D, Boit MK, Mwaniki DL, Kilonzo B, Tetens I, et al. Cardiorespiratory fitness and physical activity in Luo, Kamba, and Maasai of rural Kenya. Am J Hum Biol 2012;24:723-9.

39 Ndekha MJ, van Oosterhout JJG, Zijlstra EE, Manary M, Saloojee H, Manary MJ. Supplementary feeding with either ready-to-use fortified spread or corn-soy blend in wasted adults starting antiretroviral therapy in Malawi: randomised, investigator blinded, controlled trial. BMJ 2009;338:b1867.

40 Paton NI, Macallan DC, Jebb SA, Noble C, Baldwin C, Pazianas M, et al. Longitudinal changes in body composition measured with a variety of methods in patients with AIDS J Acquir Immune Defic Syndr Hum Retrovirol 1997;14:119-27.

41 Wanke C, Polsky B, Kotler D. Guidelines for using body composition measurement in patients with human immunodeficiency virus infection. AIDS Patient Care STDS 2002;16:375-88.

42 Welbourne TC. Increased plasma bicarbonate and growth hormone after an oral glutamine load. Am J Clin Nutr 1995;61:1058-61.

43 Shabert JK, Winslow C, Lacey JM, Wilmore DW. Glutamine-antioxidant supplementation increases body cell mass in AIDS patients with weight loss: a randomized, double-blind controlled trial. Nutrition 1999;15:860-4.

44 Shabert JK, Wilmore DW. Glutamine deficiency as a cause of human immunodeficiency virus wasting. Med Hypotheses 1996;46:252-6.

45 Heimburger DC, Koethe JR, Nyirenda C, Bosire C, Chiasera JM, Blevins M, et al. Serum phosphate predicts early mortality in adults starting antiretroviral therapy in Lusaka, Zambia: a prospective cohort study. PLoS One 2010;5:e10687.

46 Koethe JR, Heimburger DC. Nutritional aspects of HIV-associated wasting in sub-Saharan Africa. Am J Clin Nutr April 2010;91:1138-42S.

47 Kotler DP, Tierney AR, Culpepper-Morgan JA, Wang J, Pierson RN Jr. Effect of home total parenteral nutrition on body composition in patients with acquired immunodeficiency syndrome. JPEN J Parenter Enteral Nutr 1990;14:454-8.

48 Sadler K, Bontrager E, Rogers B, Coates S, Ghosh S, Kidane Y, et al. Food by prescription: measuring the impact and cost-effectiveness of prescribed food on recovery from malnutrition and HIV disease progression among HIV+ adult clients in Ethiopia. Feinstein International Center, Friedman School of Nutrition Science and Policy, Tufts University, 2012.

49 Lugassy DM, Farmer BM, Nelson LS. Metabolic and hepatobiliary side effects of antiretroviral therapy (ART). Emerg Med Clin North Am 2010;28:409-19.

Accepted: 21 April 2014

\section{Cite this as: BMJ 2014;348:g3187}

This is an Open Access article distributed in accordance with the Creative Commons Attribution Non Commercial (CC BY-NC 3.0) license, which permits others to distribute, remix, adapt, build upon this work non-commercially, and license their derivative works on different terms, provided the original work is properly cited and the use is non-commercial. See: http://creativecommons.org/licenses/by-nc/3.0/. 


\section{Tables}

Table 1| Nutrient content in $\mathbf{2 0 0} \mathrm{g}$ lipid based nutrient supplement given to patients with HIV starting antiretroviral treatment

\begin{tabular}{|c|c|}
\hline Nutrient & Amount \\
\hline Energy & $4600 \mathrm{~kJ}$ \\
\hline Fat (\% of energy) & $60 \%$ \\
\hline Carbohydrate (\% of energy) & $24 \%$ \\
\hline Total protein (\% of energy) & $16 \%$ \\
\hline Total protein & $45 \mathrm{~g}$ \\
\hline WPC $80^{*}$ or soy protein isolate $\dagger$ & $32 \mathrm{~g}$ \\
\hline \multicolumn{2}{|l|}{ Vitamins: } \\
\hline A & $1000 \mu g$ \\
\hline$\underline{D \ddagger}$ & $10 \mu g$ \\
\hline$\underline{E \ddagger}$ & $15 \mathrm{mg}$ \\
\hline $\mathrm{K \ddagger}$ & $110 \mu \mathrm{g}$ \\
\hline C‡ & $100 \mathrm{mg}$ \\
\hline B1‡ & $2.2 \mathrm{mg}$ \\
\hline B2f & $2.2 \mathrm{mg}$ \\
\hline B6‡ & $2.6 \mathrm{mg}$ \\
\hline B12‡ & $4.8 \mu \mathrm{g}$ \\
\hline Biotinef & $60 \mu \mathrm{g}$ \\
\hline$\underline{\text { Folic acid } \neq}$ & $800 \mu \mathrm{g}$ \\
\hline Panthothenic acid $\neq$ & $10 \mathrm{mg}$ \\
\hline Niacin $\ddagger$ & $28 \mathrm{mg}$ \\
\hline \multicolumn{2}{|l|}{ Minerals: } \\
\hline Calcium§ & $1000 \mathrm{mg}$ I \\
\hline Magnesium§ & $220 \mathrm{mg}$ \\
\hline Zinc $\neq$ & $6 \mathrm{mg}$ \\
\hline Iron§ & $9 \mathrm{mg}$ \\
\hline lodine§ & $110 \mu \mathrm{g}$ \\
\hline Selenium $\ddagger$ & $52 \mathrm{mg}$ \\
\hline Copperł & $3 \mathrm{mg}$ \\
\hline Manganese§ & $1 \mathrm{mg}$ \\
\hline \multicolumn{2}{|l|}{ Phosphorous**: } \\
\hline Whey & $519 \mathrm{mg}$ \\
\hline Soy & $728 \mathrm{mg}$ \\
\hline
\end{tabular}

${ }^{*}$ Whey protein concentrate $80 \%$ (Davisco Foods, Le Sueur, MN).

†Unisol Soy Isolate Protein Non GMO (Barentz (Hoofddorp, Netherlands).

$\ddagger$ Twice recommended nutrient intake (FAO/WHO $2001^{31}$ ).

§Recommended nutrient intake (FAO/WHO 2001 ${ }^{31}$ ).

ITotal amount correcting for differences in calcium content from ingredients (whey: $222 \mathrm{mg}$, soy: $77 \mathrm{mg}$ ).

${ }^{* *}$ Total amount correcting for differences in bioavailability in products. 
Table 2| Baseline characteristics of participants with HIV and BMI >17 according to lipid based nutritional supplementation given at start of antiretroviral treatment $(n=282)$. Figures are means (SD) unless stated otherwise

\begin{tabular}{|c|c|c|c|}
\hline & \multicolumn{2}{|c|}{ Early LNS* } & \multirow[b]{2}{*}{ Delayed LNS* $(n=93)$} \\
\hline & Whey $(n=94)$ & Soy $(n=95)$ & \\
\hline \multicolumn{4}{|l|}{ Demographic characteristics: } \\
\hline No $(\%)$ of women & $60(63.8)$ & $61(64.2)$ & $65(69.9)$ \\
\hline Mean (SD) age (years) & $32.2(8.0)$ & $34.5(10.3)$ & $31.7(8.5)$ \\
\hline \multicolumn{4}{|l|}{ No (\%) by education: } \\
\hline No formal schooling & $24(25.5)$ & $28(29.5)$ & $32(34.4)$ \\
\hline Primary schoolt & $48(51.1)$ & $49(51.6)$ & $43(46.2)$ \\
\hline Secondary school or higher $\dagger$ & $22(23.4)$ & $18(19.0)$ & $18(19.4)$ \\
\hline \multicolumn{4}{|c|}{ Nutritional status and energy intake: } \\
\hline Weight (kg) & $52.1(7.2)$ & $50.9(7.2)$ & $50.5(7.6)$ \\
\hline Height $(\mathrm{cm})$ & $161.2(8.1)$ & $160.7(9.0)$ & $160.0(9.2)$ \\
\hline Body mass index (BMI) & $20.0(2.2)$ & $19.8(2.5)$ & $19.8(2.1)$ \\
\hline Total energy intake (MJ/day) & $6.47(3.20)$ & $6.06(2.55)$ & $6.17(2.66)$ \\
\hline \multicolumn{4}{|l|}{ Body composition: } \\
\hline Lean body mass $(\mathrm{kg})$ & $41.9(6.3)$ & $40.9(6.2)$ & $39.9(6.8)$ \\
\hline Fat mass $(\mathrm{kg})$ & $10.3(4.6)$ & $9.9(5.5)$ & $10.6(4.8)$ \\
\hline \multicolumn{4}{|l|}{ Functional characteristics: } \\
\hline Grip strength (kg) & $24.8(6.3)$ & $24.9(6.8)$ & $24.2(6.5)$ \\
\hline PAEE $\neq(\mathrm{kJ} / \mathrm{kg} / \mathrm{day})$ & $28.6(19.1-42.7)$ & $30.0(16.3-40.4)$ & $26.8(18.6-41.0)$ \\
\hline \multicolumn{4}{|l|}{ HIV characteristics: } \\
\hline No (\%) WHO stage I/II & $62(67.4)$ & $60(63.2)$ & $52(58.4)$ \\
\hline No (\%) WHO stage III/IV & $30(32.6)$ & $35(36.8)$ & $37(41.6)$ \\
\hline Viral load $(\log (1+$ copies $/ \mathrm{mL}))$ & $4.77(0.95)$ & $4.65(1.05)$ & $4.67(0.78)$ \\
\hline CD3 ( cells $/ \mu \mathrm{L}$ ) & $1215(966)$ & $1134(557)$ & $1138(487)$ \\
\hline CD4 (cells/uL) & $181(94)$ & $191(110)$ & $191(106)$ \\
\hline CD8 (cells/ $/ \mu \mathrm{L})$ & $876(418)$ & $875(444)$ & $880(414)$ \\
\hline
\end{tabular}

LNS=lipid based nutrient supplement; PAEE=physical activity energy expenditure.

*Early LNS groups received supplement during first three months. Delayed LNS group received supplement during subsequent three months. †Includes all with some/complete education level.

‡Median (interquartile range). Data available for 71 in early LNS/whey group, 60 in early LNS/soy group, and 64 in delayed LNS group. 
Table 3| Differences in outcomes at three months between participants with HIV and BMI >17 ( $n=282)$ allocated to early or delayed lipid based nutrient supplement with whey or soy at start of antiretroviral treatment. Effect estimates are presented with $95 \% \mathrm{Cl}$ and adjusted for sex, age, and education

\begin{tabular}{|c|c|c|c|}
\hline & \multicolumn{2}{|c|}{ Early LNS* } & \multirow[b]{2}{*}{ Delayed LNS* $(n=93)$} \\
\hline & Whey $(n=94)$, P value & Soy $(n=95)$, P value & \\
\hline \multicolumn{4}{|l|}{ Primary outcomes: } \\
\hline Lean body mass $†$ (kg) & 0.85 (0.16 to 1.53$), 0.018$ & 0.97 (0.29 to 1.64$), 0.005$ & Reference \\
\hline Grip strength, kg) & $0.68(-0.11$ to 1.46$), 0.090$ & 0.93 (0.16 to 1.70$), 0.019$ & Reference \\
\hline PAEE $\neq(\mathrm{kJ} / \mathrm{kg} /$ day ) & 1.06 (0.87 to 1.29$), 0.56$ & 1.10 (0.91 to 1.33 ), 0.31 & Reference \\
\hline \multicolumn{4}{|l|}{ Secondary outcomes: } \\
\hline Viral load $(\log (1+$ copies $/ m L))$ & $-0.02(-0.38$ to 0.34$), 0.91$ & $-0.01(-0.37$ to 0.34$), 0.94$ & Reference \\
\hline CD4 (cells/ $\mu \mathrm{L})$ & 25 (-2 to 53$), 0.073$ & $15(-12$ to 42$), 0.28$ & Reference \\
\hline \multicolumn{4}{|l|}{ Auxiliary outcomes: } \\
\hline CD3 (cells $/ \mu \mathrm{L})$ & 150 (24 to 275), 0.020 & 79 (-44 to 202$), 0.21$ & Reference \\
\hline CD8 (cells/ $\mu \mathrm{L})$ & 112 (15 to 209), 0.023 & $60(-35$ to 154$), 0.22$ & Reference \\
\hline Weight† (kg) & 2.05 (1.12 to 2.99$),<0.001$ & 2.06 (1.14 to 2.97$),<0.001$ & Reference \\
\hline
\end{tabular}

LNS=lipid based nutrient supplement; PAEE=physical activity energy expenditure.

*Early LNS groups received supplement during first three months. Delayed LNS group received supplement during subsequent three months. †Lean body mass and weight adjusted for height.

ҒEffect estimates back transformed from log scale. Data available for 33 in early LNS/whey group, 34 in early LNS/soy group, and 31 in delayed LNS group. 
Table 4| Differences in outcomes at three months between participants with HIV and BMI >16 $(n=225)$ allocated to lipid based nutrient supplement with whey or soy during first three months of antiretroviral treatment. Effect estimates are presented with $95 \% \mathrm{Cl}$ and adjusted for sex, age, and education

\begin{tabular}{|c|c|c|c|}
\hline & Whey $(n=112)$ & Soy $(n=113)$ & $P$ value \\
\hline \multicolumn{4}{|l|}{ Primary outcomes: } \\
\hline Lean body mass* $(\mathrm{kg})$ & $-0.18(-0.82$ to 0.45$)$ & Reference & 0.58 \\
\hline Grip strength $(\mathrm{kg})$ & $-0.50(-1.21$ to 0.21$)$ & Reference & 0.16 \\
\hline PAEE† (kJ/kg/day ) & $0.96(0.82$ to 1.14$)$ & Reference & 0.66 \\
\hline \multicolumn{4}{|l|}{ Secondary outcomes: } \\
\hline Viral load $(\log (1+$ copies $/ \mathrm{mL}))$ & $-0.04(-0.35$ to 0.27$)$ & Reference & 0.80 \\
\hline CD4 (cells/ $\mu \mathrm{L})$ & $8(-21$ to 37$)$ & Reference & 0.58 \\
\hline \multicolumn{4}{|l|}{ Auxiliary outcomes: } \\
\hline CD3 (cells/ $\mu \mathrm{L})$ & $37(-87$ to 160$)$ & Reference & 0.56 \\
\hline CD8 (cells/ $\mu \mathrm{L})$ & $31(-57$ to 119$)$ & Reference & 0.49 \\
\hline Weight $^{*}(\mathrm{~kg})$ & $-0.41(-1.27$ to 0.46$)$ & Reference & 0.36 \\
\hline
\end{tabular}

LNS=lipid-based nutrient supplement; PAEE=physical activity energy expenditure.

*Lean body mass and weight adjusted for height.

†Effect estimates back transformed from log scale. Data available for 39 in whey group and 43 in soy group. 


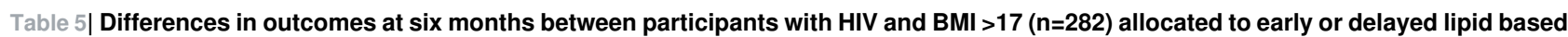
nutrient supplement (whey and soy) at start of antiretroviral treatment. Effect estimates are presented with $95 \% \mathrm{Cl}$ and adjusted for sex, age, and education

\begin{tabular}{|c|c|c|c|}
\hline & Early LNS* $(n=189)$ & Delayed LNS* $(n=93)$ & $P$ value \\
\hline \multicolumn{4}{|l|}{ Primary outcomes: } \\
\hline Lean body mass* $(k g)$ & Reference & $0.36(-0.23$ to 0.94$)$ & 0.23 \\
\hline Grip strength (kg) & Reference & $-0.84(-1.53$ to -0.04$)$ & 0.018 \\
\hline PAEE† (kJ/kg/day) & Reference & $0.78(0.65$ to 0.95$)$ & 0.012 \\
\hline \multicolumn{4}{|l|}{ Secondary outcomes: } \\
\hline Viral load $(\log (1+$ copies/mL $))$ & Reference & $0.06(-0.24$ to 0.37$)$ & 0.68 \\
\hline CD4 (cells/ $\mu \mathrm{L})$ & Reference & $-6(-31$ to 18$)$ & 0.62 \\
\hline \multicolumn{4}{|l|}{ Auxiliary outcomes: } \\
\hline CD3 (cells $/ \mu \mathrm{L})$ & Reference & $-26(-132$ to 79$)$ & 0.63 \\
\hline CD8 (cells/ $\mu \mathrm{L})$ & Reference & $-24(-107$ to 60$)$ & 0.58 \\
\hline Weight* $(k g)$ & Reference & 1.20 (0.32 to 2.09$)$ & 0.008 \\
\hline
\end{tabular}

LNS=lipid based nutrient supplement; PAEE=physical activity energy expenditure.

*Early LNS groups received supplement during first three months of antiretroviral treatment. Delayed LNS group received supplement during subsequent three months.

†Lean body mass and weight adjusted for height

¥Effect estimates back transformed from log scale. Data available for 77 in early LNS group and 36 in delayed LNS group. 


\section{Figures}

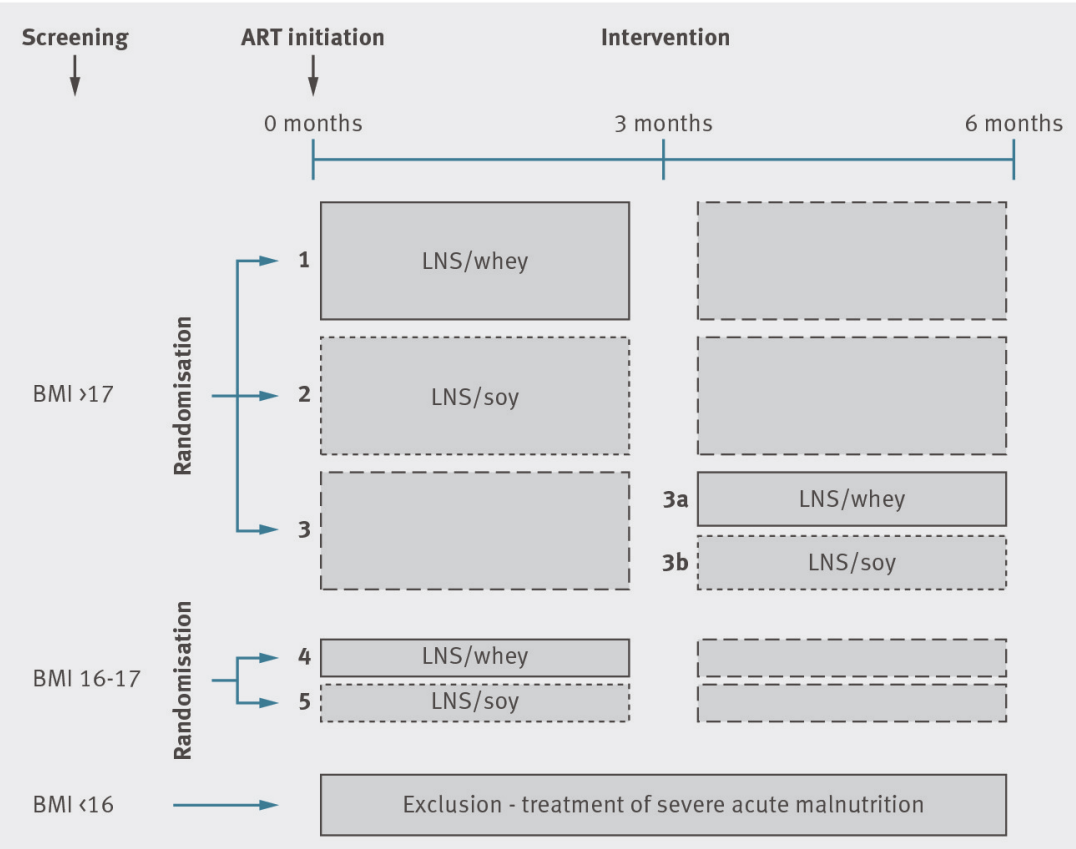

Fig 1 Study design with randomisation of participants stratified by BMI (LNS=lipid based nutrient supplement)

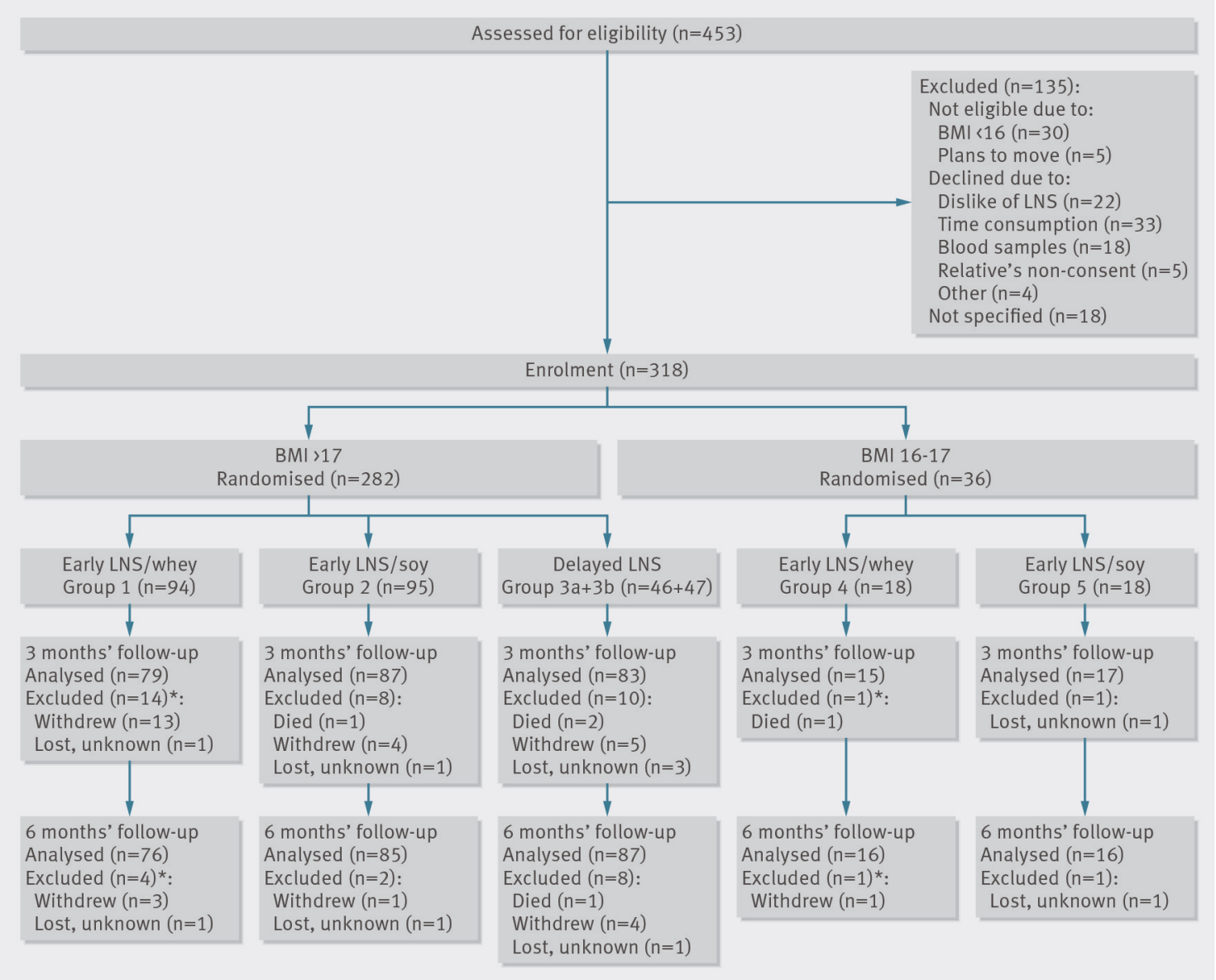

Fig 2 Flow chart of enrolment of participants and follow-up (LNS=lipid based nutrient supplement). *Numbers do not add up because of missed visits 

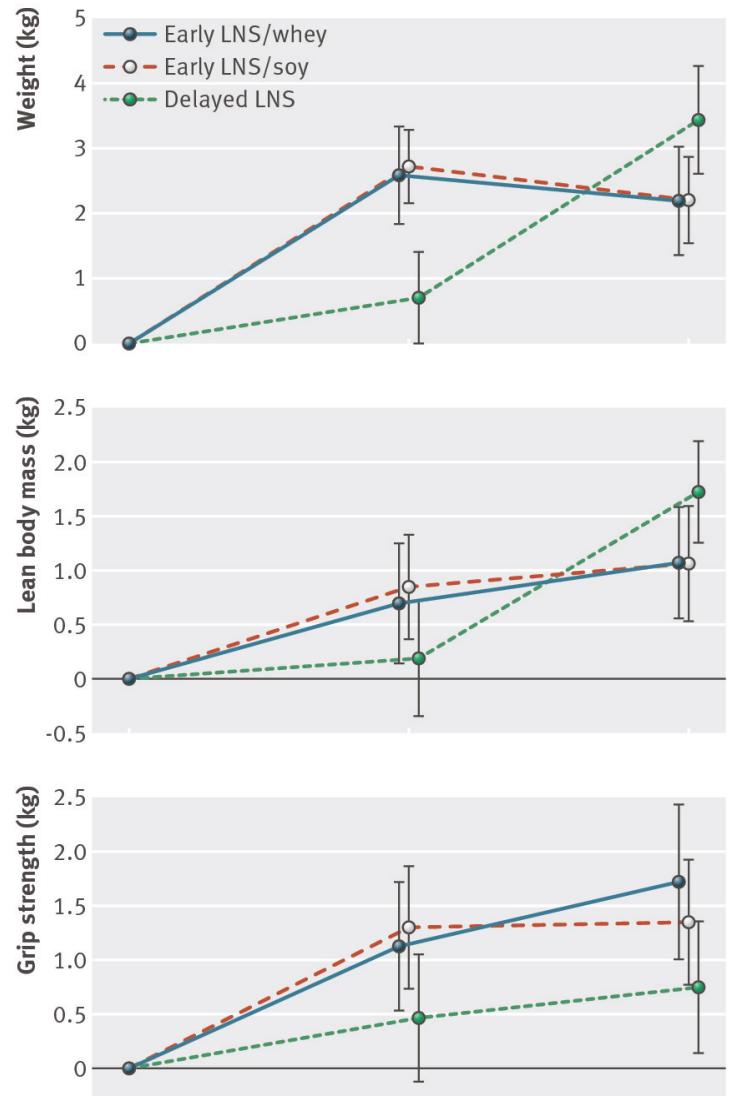

$-0.5$

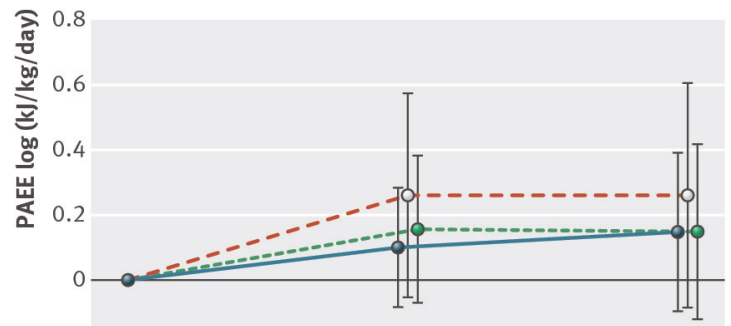

$-0.2$
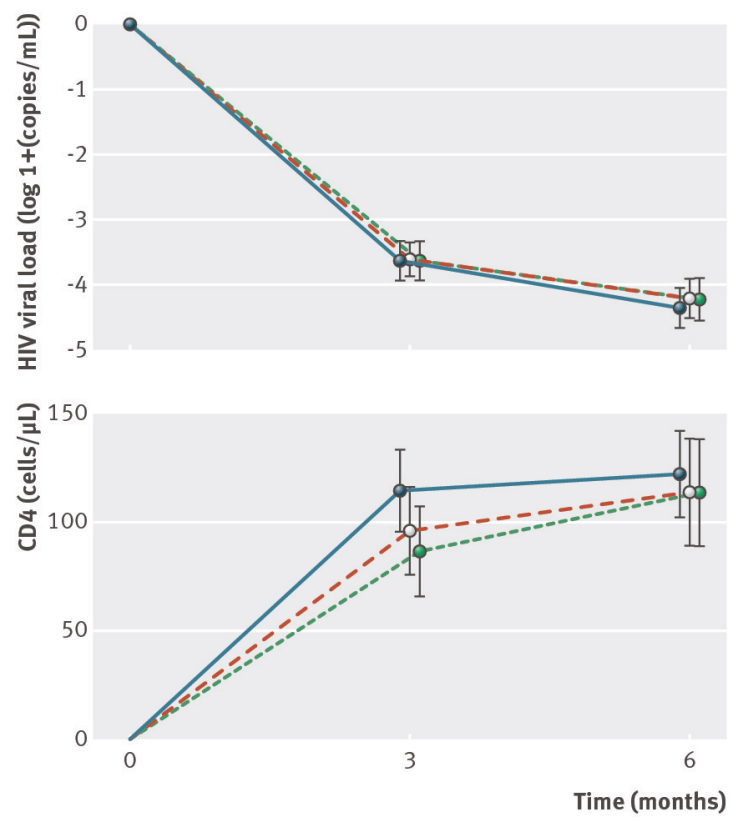

Fig 3 Changes in weight, lean body mass, grip strength, physical activity energy expenditure (PAEE), HIV viral load, and CD4 count by intervention group. Graphs present unadjusted means with indication of $95 \%$ confidence interval for participants with complete data and $\mathrm{BMI}>17$ (LNS=lipid based nutrient supplement) 